\title{
Strengthening Health Systems for Evidence-informed Policy Making
}

\author{
ChandRaKant LAHARIYA \\ B-7/24/2, First Floor, Safdarjung Enclave Main, New Delhi-110 029, India \\ c.lahariya@gmail.com
}

S afety and efficacy are amongst the key criteria prior to the licensing and marketing authorization of vaccines by national regulatory authorities across the world. The principle that benefits should outweigh the (small) risk associated with vaccine administration is upheld. The safety assessment of vaccines requires continuous surveillance of the risks associated with vaccine administration, which in turn requires - among other mechanisms - a functioning system to record and report any health event that may follow vaccination. In India, the first documented investigation of an adverse event after vaccination goes back to as early as the year 1902 [1]. Decades later, a formal monitoring mechanism to record and report adverse events following vaccination as part of national program was outlined at the launch of Universal Immunization Program (UIP) in India in 1985 [2]. Thirty years since then, the Adverse Events Following Immunization (AEFI) surveillance system in India has come a long way, and now there are mechanisms of case-based surveillance and investigation of serious AEFIs, while non-serious (or minor) AEFIs are reported and documented through routine and aggregate reporting mechanism [3].

In the last two decades, the vaccines against a number of additional disease-causing agents have been licensed in countries with different income levels. While the use of newer vaccines is widespread in high income countries, the availability of these vaccines in majority of low- and middle-income countries (LMICs) is restricted to physicians in the private sector offering vaccination services. Moreover, the availability and accessibility of information about vaccines on the World Wide Web has not only led to the increased demand for vaccination but also for information on the safety of vaccines. What is applicable to vaccines as one of the health interventions is also applicable for any other health intervention. The demand for information on any aspect of vaccination (including on the safety) is invariably higher than the health systems in LMICs are prepared and capable to generate. In this background, innovative approaches to gather additional information on new health interventions have to be explored and optimally utilized.
This issue of Indian Pediatrics publishes a study by Kompithra, et al. [4], that compares the common illnesses before and after vaccination through 'risk interval approach'. The study has been conducted at a tertiary care level health facility in private sector in a state in Southern part of India [4]. A key finding reported is that with the exception of fever, rates of other common childhood illnesses reported before vaccination were higher than in the post-vaccination period. From the literature cited in this study, one can notice that there may not be many studies (at least published) on this topic from India. This is probably one of the first published studies to systematically compare the common illnesses before and after vaccine administration (often termed non-serious AEFIs) from Indian settings. Though, there are methodological limitations in this study as also mentioned by the authors, these should be considered as learning points by researchers to design better studies in future. One of the strengths of this study is that the comparative analysis presented by the authors is not possible through existing aggregate reporting mechanisms for non-serious AEFIs in India.

This study could be an appropriate starting point for more research to generate comparable data from public and private sector and different geographical locations in the country. Such data could prove extremely useful for decision-making on the introduction of newer vaccines as often requested by technical committees such as National Immunization Technical Advisory Groups, prior to the recommendations on the inclusion (or not) of newer vaccines in the national immunization programs of a country. The newer vaccines become available in the private sector soon after licensing by regulatory body of a country. In LMICs, there is average time lag of 10-15 years before such vaccines become part of public vaccination program. In this context, evidence generated through sufficiently robust scientific methodology (on safety and other aspects) could be a valuable source of additional data for decision-making. For example, in India private sector provides vaccination to nearly $10-20 \%$ of approximately 125 million under-five children. Therefore, data from even a fraction of this cohort over period of a few years could be a large evidence base. 
TABLE I StaKeholder ENGagement For IMPROVIng VACCINE SAFETy

\begin{tabular}{|c|c|c|c|}
\hline Stakeholders & Tools & Funding & $\begin{array}{l}\text { Coordination } \\
\text { mechanisms }\end{array}$ \\
\hline $\begin{array}{l}\text { Parents/Caregivers/ } \\
\text { Community/Public }\end{array}$ & $\begin{array}{l}\text { Existing reporting mechanisms } \\
\text { (both offline and online) }\end{array}$ & $\begin{array}{l}\text { Government Ministries of } \\
\text { Health (Union and States) }\end{array}$ & $\begin{array}{l}\text { Data collation from all } \\
\text { sources, including public } \\
\text { and private sector } \\
\text { coordination }\end{array}$ \\
\hline $\begin{array}{l}\text { Governments (Union and } \\
\text { state levels) }\end{array}$ & $\begin{array}{l}\text { Scientific data and } \\
\text { research papers }\end{array}$ & $\begin{array}{l}\text { Autonomous research } \\
\text { councils and other depart- } \\
\text { ments promoting research }\end{array}$ & \\
\hline $\begin{array}{l}\text { Academia and research } \\
\text { institutions }\end{array}$ & $\begin{array}{l}\text { Information and } \\
\text { communication } \\
\text { technology, } \\
\text { including } \\
\text { mobile-based } \\
\text { applications }\end{array}$ & $\begin{array}{l}\text { External donor assistance } \\
\text { including international } \\
\text { development partners }\end{array}$ & $\begin{array}{l}\text { Institutional mechanisms } \\
\text { to facilitate the decision- } \\
\text { making platform for } \\
\text { information exchange, } \\
\text { sharing of information } \\
\text { and best practices }\end{array}$ \\
\hline $\begin{array}{l}\text { Physicians who } \\
\text { administer vaccines } \\
\text { (both public and private) }\end{array}$ & Print and electronic media & $\begin{array}{l}\text { Industry through grants } \\
\text { and corporate social } \\
\text { responsibility } \\
\text { contributions }\end{array}$ & $\begin{array}{l}\text { Coordination for } \\
\text { academia, technical } \\
\text { committees, } \\
\text { independent experts, key }\end{array}$ \\
\hline $\begin{array}{l}\text { Professional bodies and } \\
\text { associations }\end{array}$ & $\begin{array}{l}\text { Social media and the public } \\
\text { websites for reporting by } \\
\text { layman }\end{array}$ & Autonomous bodies & $\begin{array}{l}\text { makers and program } \\
\text { managers }\end{array}$ \\
\hline
\end{tabular}

The information generated by this study is valuable. However, such studies should not be the only source of data, and there is a need for systematic institutional mechanisms for long-term evidence generation. The health systems and surveillance mechanisms in LMICs should be strengthened by specific focus upon areas such as improving immunization service delivery to additional populations, providing additional financial resources, capacity building of staff at various levels in data collection, reporting and analysis, preparing conducive and supportive policies, and providing leadership at all levels. Such efforts require involvement of wider numbers of stakeholders. There is a need for working through a comprehensive framework (Table I) on the inclusion of stakeholders, with possible tools, funding sources and coordinating mechanisms, to streamline the dialogue and strengthen the health systems in more coordinated ways to improve immunization services in LMICs.

The health systems in LMICs need to be prepared to generate information to assist policy makers in all relevant aspects of decision-making components. Every opportunity, which comes our way, should be used to reflect upon the need for institutional mechanisms and health systems for strengthening the evidence-based policy decision making. It is up to the stakeholders to decide together on how quickly they would like to act upon what needs to be done at the earliest possible.

Funding: None; Competing interests: None stated.

Disclaimer: The views expressed are personal and do not necessarily represent the decisions, policy, or views of organizations and institutions the author has been affiliated in past or at present.

\section{REFERENCES}

1. Lahariya C. A brief history of vaccines \& vaccination in India. Indian J Med Res. 2014;139:491-511.

2. Sokhey J. Adverse events following immunization:1990. Indian Pediatr. 1991;28:593-607.

3. Government of India. Adverse Event Following Immunization: Surveillance and Response Operational Guidelines 2015. Ministry of Health and Family Welfare, Government of India, Nirman Bhawan, New Delhi. 2015.

4. Kompithra RZ, Sarkar R, Mathew LG, Muliyil J, Kang G. Study of common illnesses before and after vaccination: A risk-interval approach. Indian Pediatr. 2015;52:933-8. 